\title{
Multimodal Discourse Analysis of the Movie Argo
}

\author{
$\mathrm{Xu} \mathrm{Bo}{ }^{1}$ \\ ${ }^{1}$ Binhe Road 778\#, Shizhong District, School of Foreign Languages, Leshan Normal University, Leshan, \\ Sichuan, China \\ Correspondence: Xu Bo, Binhe Road 778\#, Shizhong District, School of Foreign Languages, Leshan Normal \\ University, Leshan, Sichuan, China. E-mail: 419934369@qq.com
}

Received: November 4, 2017 Accepted: March 24, 2018 Online Published: March 26, 2018

doi: $10.5539 /$ elt.v11n4p132

URL: http://doi.org/10.5539/elt.v11n4p132

\begin{abstract}
Based on multimodal discourse theory, this paper makes a multimodal discourse analysis of some shots in the movie Argo from the perspective of context of culture, context of situation and meaning of image. Results show that this movie constructs multimodal discourse through particular context, language and image, and successfully publicizes western mainstream ideology.
\end{abstract}

Key words: Argo, movie, multimodal discourse analysis, context

\section{Introduction}

Multimodal discourse analysis refers to the analysis of various and different semiotic modes in a discourse. The aim of it is to integrate the representational, interactive and textual meanings achieved by various elements. Its task is to analyze how these elements work together to form a complete discourse. As a matter of fact, in current writing, textual structure is realized not only by linguistic signs, but also by layout, color, and typography both at the level of "clause" and at the level of "discourse" (Wei, 2015).

Multimodal discourse analysis can be done in many ways; content analysis, conversation analysis, and social semiotic analysis belong to it. And different perspectives can be taken to analyze them. For example, we can select elements such as layout, modality, color, genre, discourse, style, etc. to do multimodal discourse analysis.

Multimodal discourse analysis is a new and rapidly developing research hot spot in discourse analysis field. It has become very popular in the western world since 1990s.

Since then, discourse analysis has laid emphasis on linguistic sign the mono-modality. Recently, discourse analysis has changed its field from static to dynamic multimodal discourse analysis - including sound, language, image and action. Multimodal discourse refers to using visual, audio, sense multi-lingual symbol system to communicate through multi-means and symbol recourses such as character, image, sound and action. (Zhang, 2009).

Movie Argo is about an agent Tony Mendez from CIA. He was adept at camouflage technology and designed a rescue plan in which six American diplomats trapped in Embassy of Canada in Iran were saved. Obviously, movie belongs to multimodal discourse, thus, the movie Argo can be analyzed from three perspective of multimodal discourse analysis: context of culture, context of situation and the meaning of image.

\section{Literature Review}

Scholars both in China and abroad have done researches on multimodal discourse from different aspects. Kress and Van Leewuen (2006) discussed image and visual design. O'Toole (2010) applied systemic functional mode to arts, painting, sculpture and architecture symbols. Kay O'Halloran (2011) made a multimodal discourse analysis of Australian multi-party debate.

Recently, scholars in China have been doing research on multimodal discourse analysis. Linguistic semiotics has made an immense contribution to the development of general semiotics, but it has met challenges from some researchers in this domain. Based on Halliday's theory of language as social signs, social semiotics puts emphasis on the semiotic practices of a particular community of a particular culture, which pushes forward the study of multimodal presentations, i.e. the multimodal semiotics. Hu (2007) differentiated multimodal semiotics from multimedia semiotics; the former was based on the view that all discourses inherently possess the nature of multimodality; then it went on discussing the role of computer semiotics. He also dealt with some relevant 
problems, such as semiotic resources as semiotic system, the replacement of books with screens in the designing of multimodal signs, and coherence realized by discourse participants. Since we live in a new era characterized by multimodal social semiotics, we should pay attention to the training of one's multi-literacy.

So far, the discourse analysis has been focusing on language itself, some on the language system and semantic structure, others on their relation to culture and cognition. Zhu (2007) made an attempt to discuss many issues relevant to multimodal discourse analysis: the origin, definition, nature, theoretical basis, content, methodology and significance of multimodal discourse ( $\mathrm{Zhu}, 2007$ ).

Taking advantage of a PowerPoint presentation sponsored by Renmin University's Australian Studies Center, Hu and Dong (2006) made an analysis of 23 PowerPoint presentation texts, thinking that PowerPoint presentation is a very important information communication tool and has become a new genre. Results show that natural language is still the main modality to convey meaning. The power of PowerPoint presentation lies in application of the image and sound in conveyance of thematic meaning. It is necessary that we should distinguish PowerPoint is a tool, a text or a genre.

Ye (2006) interpreted multimodality of hypertext on the basis of people's website. He made an analysis of a social semiotic account of multimodal texts, the visual space, states of affairs and the social relations of the viewer and the image as well.

Based on the theory of systemic functional linguistics, language functions and interactive mode, Huang and Liao (2008) explored the process of communicative interaction and meaning negotiation in CNN TV interview program: Larry King Live. Results show that there are three linguistic interactive mode: cooperation, provocation and avoidance. Xu applied multimodal discourse analysis of the disaster Movie 2012(Xu, 2012).

Tian and Zhang (2013) applied Kress and van Leeuwe's Visual Grammar to a multimodal discourse analysis of images on the Olympic torch lighting ceremony. The ideologies hidden in the Chinese and British media was revealed by them. Study shows that the media agents have expanded its image from representative meaning, interactional meaning and compositional meaning to different ideologies.

Based on visual grammar in semiotics, Li (2013) interpreted multimodality of advertisement hypertexts, including multimodality in semiotics, space division in visual discourse, meaning of tourism image advertisement and social relations between reader and images. It is feasible to apply visual grammar in advertisement hypertexts, which is good to understand text and significant to improve multi-literacy and appreciation competence.

The multimodal discourse has been paid much more attention to. People were interested in the multimodality of discourse long time ago. However, it took a long time for scholars to realize its importance (Dai, 2013). Although language is a very important resource in discourse, yet it needs to coordinate with other resources in the process of meaning-making. Therefore, discourse analysis should take other modalities into consideration. In the near future, multimodal discourse will need more concern from researchers. Zhao (2016) made a multimodal discourse analysis of movie posters, taking movie Tiny Times as an example.

Dai (2017) discussed the relationship between language, image, motion, posture, sound and other modalities .It is very important to realize the construction of meaning depending on the coordination of different semiotic resources. Interactive sociolinguistics and cognitive linguistics pool their researching efforts into the relationship of different modalities in multimodal discourse. He attempted to probe into and revealed the discourse features of multimodal discourse, hence, enhanced the understanding and cognition of the relationship between different modalities.

Researchers at home and abroad has applied more and more modalities into the filed of multimodality, such as sound and music, science textbook, education research, action and gesture, multi-literacy. Multimodality discourse analysis has been expanded to field such as newspaper, advertisement, television interview, PPT, hypertext and movie, etc.

\section{Multimodal Discourse Analysis of the Movie Argo}

Based on systemic functional grammar put forward by Hallliday (2006), Zhang (2009) formed the theoretical framework of multimodal discourse analysis, which includes five levels: culture, context, meaning, form and media. Based on the framework, the author of the paper will make a multimodal discourse analysis of the movie Argo from the perspective of context of culture, context of situation and meaning of the image.

In the first place, context of culture is realized via ideology and genre, which is an important element in multimodality communication. Context of culture is so vital that context of situation is dependent on it. In 
context of culture, Argo can be categorized as Hollywood theme movie in which American pursues liberty and respects the value of life. Democracy and liberty of American government comes up in the movie, which sets a good example of American government. In addition, the movie sets a positive image which caters for the United States, Britain, and Canada through intelligence cooperation and advocates western mainstream ideology. Under the circumstance, Iran is seen as a villain role, which opposes western world.

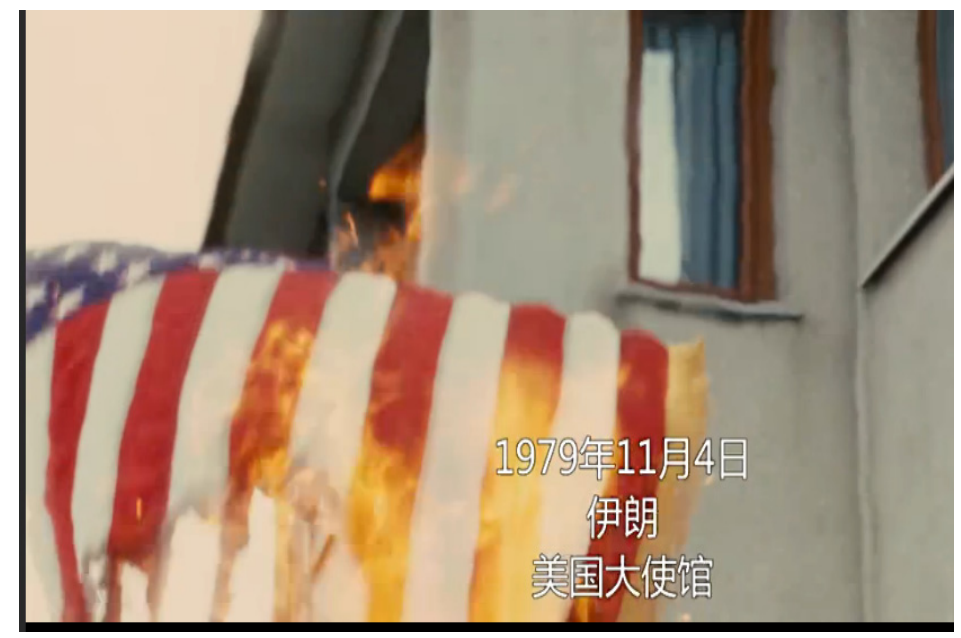

Scene one: Burning of American national flag

Splendid shot one: American national flag. In the beginning of the movie, the director tells the origin and background information of the movie through cartoon, pictures and a series of historical video. American national flag has shown in the movie for several times, from extreme political action_— burning of American national flag to the flag hung in the laundry, American national flag drawn by the American people, praying for the American people, American national flag in the Iran embassy. The burning of Iran national flag is also publicized in the perspective of American discourse privilege. It is obvious that American political space and discourse power should be advocated in the movie. Burning American national flag, "God bless American" called out by American people, American people's support for war advocates a fact that the United States of America is a democratic political country. In America, people can make comment on politics freely in spite of any restrictions from institution, for their country is a nation with discourse power in which the society is harmonious and stable. Any political event will not exert any influence on people's stable life.

Although Iran in the movie is a country free of political discourse power, people in the country is out of order. In the beginning of the movie, frame is continually shaking and people in demonstration are ferocious and brutal: some are tearing Reza's picture; some are covering American diplomat's eyes...the scene testifies that only America is the most democratic and beautiful country. The movie advocates American spirit in a classic way.

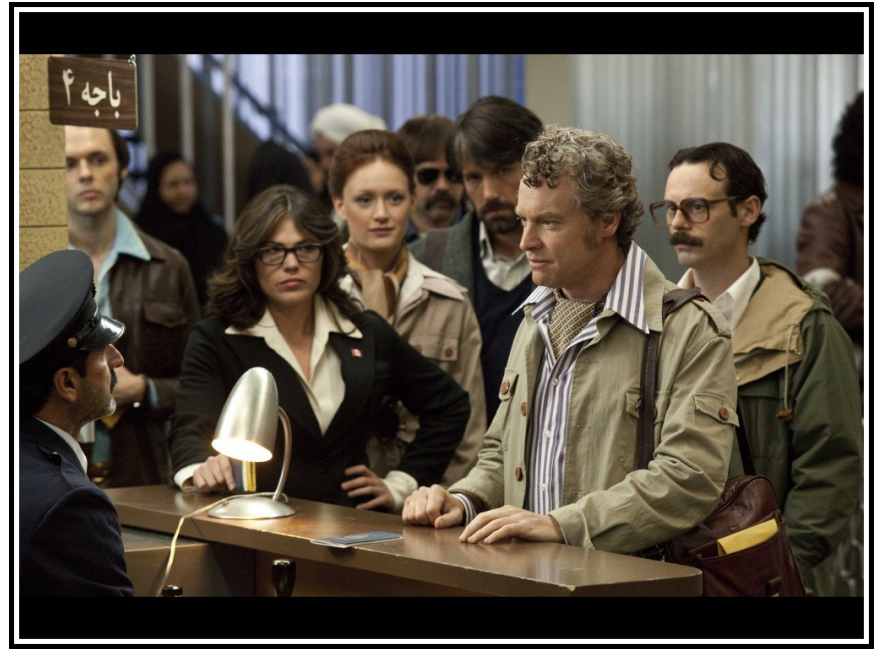

Scene two: Six diplomats in security office 
In the second place, the context of situation is achieved via field of discourse, mode of discourse and tenor of discourse. The field of discourse of Argo is that agent Tony Mendez designed a recue plan through making a movie named Argo and successfully brought six American diplomats trapped in Canadian embassy in Iran away.

The tenor of discourse of Argo is realized through dialogues made by Tony Mendez, Jack Donnell, Lester Siegel, the Central Intelligence agency leader, and John Chambers, Hollywood movie producer. The tenor is achieved through formal and informal dialogues, mainly formal language, interactive communication or a combination of formal and informal language.

The mode of the discourse of Argo is a movie discourse which is realized through language, image, sound and sensory organs and the four elements are supplementary to each other.

Finally, at meaning of image level, field of discourse, mode of discourse and tenor of discourse of the situational context are achieved through representational meaning, interactive meaning and compositional meaning. One classic shot is selected here. The time duration of Argo from the beginning to the parade burning American national flag outside American embassy in Iran, and assault to the embassy is 3 minutes 30 seconds. This movie clip tells Iran history and the process how Reza Baleway supported by America and Britain is overturned and sought for asylum in America through a serious of actions: parade's burning of American national flag and assault to the embassy through black and white documentary, caricature and colorful video.

Based on Kress and van Leewuen's (2006) distinction, frame belongs to narrative image. The representational meaning of the image is embodied by action process, reactional process, and speech and mental process. Action process are Mohammad Mosaddegh's nationalizing petrol company held by American and British company, returning Iran petrol to Iran people; Reza Baleway supported by America and Britain lived on the fat of the land whereas people had not sufficient food to eat. The whole nation was held down by his brutal rule; Parade people tore apart the picture of the king and assaulted embassy, etc. Reactional processes include people's overthrowing the king, the parade outside the embassy, burning of American national flag, calling for extradition of the king back to Iran. Shouting and expressions of the parade belong to speech and mental process.

Interactive meaning of the image is mainly achieved through contact, social distance and attitude (Wei, 2015). Scenes in Argo such as parade people's burning of American national flag outside American embassy in Iran, impact on embassy make the audience feel the change of Iran political power. Burning of American national flag and impact on American embassy in Iran construct a negative image of Iran leader. As for the people in parade, the movie found the view from far to near or a combination of far view and near view. Burning of American national flag finds the view from near to far, which closes the distance between actors and audience and enhances the emotional communication to each other and makes the audience think that political situation in Iran is in chaos: people in parade detained diplomats at their own will. Attitude expresses a point of view. In visual communication attitude is about angels or perspectives. High angle is used in parade, which makes audience be afraid of the parade. For the image of the burning of American national flag at the top of the embassy building, low angles are used first and then high angles are used too, which makes the audience have a felling of awe. For the image of people tearing the photo of Reza Baleway, horizontal perspective is used to make the audience feel that they are personally on the scene.

Compositions, that is, the representational and interactive meanings are combined into a unity of significance. Information value, salience and framing constitute the compositional meaning of image (Kress \& Van Leeuwen, 2006). Different elements are placed in different places, thus conveying specific information, which is called information value. For instance, given information is put in the left whereas the new information is placed in the right. The ideal information is placed at the top while the real information is put at the bottom.

When introducing background information about the movie, the photographer placed Iran King and Prime Minister in the center and the information value is in the center of the picture, which is consistent with the centre composition principle: in the centre is the important information and around them are the less important elements. Certain features in a composition comprise salience. In the beginning of the background information, the introduction to Iran leader, Reza Baleway and the maltreated person are put in the centre of the image, which makes the audience know the background of Iran leader. Framing devices includes lines or the outlines and so on. Using these framing devices can separate or relate different elements. The clip is a combination of backdrop and theme from the perspective of framing. The picture and cartoon in the beginning of the movie clip belongs to background element, thus black and white color is used here, which make the audience think that it is real historical fact. People in the parade burning American national flag and assault to American embassy are theme elements which use chromatic tone, thus making the audience return to the reality. 


\section{Conclusion}

In conclusion, based on the theoretical framework of multimodal discourse analysis, the paper made a multimodal discourse analysis of the movie Argo clip (3 minutes 30 seconds) from the perspective of context of culture, context of situation and image meaning. Results show that the clip constructs multimodal discourse through specific context (namely context of culture and context of situation), language, image, and consequently, advocates western mainstream ideology successfully.

The paper applies multimodal discourse analysis to feature and horror movie, which expands the research field of multimodal discourse analysis, testifies the feasibility and operability of applying multimodal discourse analysis to feature and horror movie. At the same time, the paper integrates discourse, movie and television media which also develops interface research field of linguistics, movie and television media. Hence, it provides a new research perspective for discourse analysis of movie and television media.

\section{Acknowledgements}

This paper is supported by a grant from Sichuan Provincial Department of Education (Project name: Research of Multimodal Discourse of Chinese and American TV News Magazine; Project number: 17SB0171).

\section{References}

Dai, S. L. (2013). The Origin and Development of Multimodal Discourse Analysis. Foreign Language Research, $2,17-23$.

Dai, S. L. (2017). On the Relationship of Different Modalities in Multimodal Discourse. Foreign Language Research, 6, 1-7.

Halliday, M. A. K. (2006). An Introduction to Functional Grammar (2nd ed.). London: Edward Arnold/ Beijing: Foreign Language Teaching and Research Press.

$\mathrm{Hu}, \mathrm{Z}$. L. (2007). Multimodalization in Social Semiotics. Language Teaching and Research, 1, 1-10.

Hu, Z. L., \& Dong, J. (2006). How is Meaning Construed Multimodally-A Case Study of a PowerPoint Presentation Context .Computer Assisted Foreign Language Education, 6, 3-12.

Huang, G. W., \& Liao, H. Q. (2008). Function and Interactive Mode of TV Interview Program, Foreign Languages Research, 4, 1-9.

Kress, G., \& van Leeuwen, T. (2006). Reading Images: The Grammar of Visual Design (2nd ed.). London: Routledge.

Li, D. Z. (2013). Visual Grammar Analysis of Multimodality Advertisement Hypertext. Foreign Language Research, 2, 7-11.

O’Halloran, K. L. (2011). Multimodal Discourse Analysis. In K. Hyland, \& B. Paltridge (Eds.), Companion to Discourse (pp. 1-33). London and New York: Continuum.

O'Toole, M. (2010). The Language of Displayed Art (2nd ed). London and New York: Routledge.

Tian, H. L., \& Zhang, X. J. (2013). Meanings in Images and Ideologies of Media: A Multimodal Discourse Analysis, Foreign Language Research, 2, 1-6.

Wei, Q. H. (2015). Studies on Multimodality and Multimodal Discourse in Visual Surroundings. Beijing: Science Press.

Xu, B. (2011). A Multimodal Discourse Analysis of the Movie 2012.Movie Literature, 9, 81-82.

Ye, Q. C. (2006). A social semiotic analysis of hypertext's multimodality. Foreign Language Teaching and Research (bimonthly), 6, 437-442.

Zhang, D. L. (2009). On A Synthetic Theoretical Framework for Multimodal Discourse Analysis .China Foreign Language, 1, 24-30.

Zhao, C. P. (2016). Multimodal Discourse Analysis of Movie Posters-Taking Tiny Times as an Example, Movie Review, 12, 110-112.

Zhu, Y. S. (2007). Theory and Methodology of Multimodal Discourse Analysis. Foreign Language Research, 5, $82-86$. 


\section{Copyrights}

Copyright for this article is retained by the author(s), with first publication rights granted to the journal.

This is an open-access article distributed under the terms and conditions of the Creative Commons Attribution license (http://creativecommons.org/licenses/by/4.0/). 